\title{
Growth inhibition and apoptosis induction in ovarian cancer cells
}

\author{
RANIA TOUMA ${ }^{1}$, SABINE KARTARIUS ${ }^{1}$, ANTONINA HARLOZINSKA ${ }^{2}$, \\ CLAUDIA GÖTZ ${ }^{1}$ and MATHIAS MONTENARH ${ }^{1}$
}

\author{
${ }^{1}$ Universität des Saarlandes, Medizinische Biochemie und Molekularbiologie, Gebäude 44, D-66421 Homburg, Germany; \\ ${ }^{2}$ Wroclaw University of Medicine, Department of Tumor Immunology, Mikulicza-Radeckiego 7, 50-368 Wroclaw, Poland
}

Received January 11, 2006; Accepted March 20, 2006

\begin{abstract}
Standard therapy for the treatment of ovarian cancer is radical surgery followed by radiation and/or chemotherapy using cisplatin and paclitaxel. Unfortunately, some patients relapse after this first line chemotherapy and some patients become platinum-refractory. Therefore, we analyzed two different ovarian carcinoma cell lines for their sensitivity for $\gamma$ irradiation and treatment with cisplatin, irinotecan, paclitaxel and gemcitabine. We found that both cell lines were rather resistant against $\gamma$-irradiation and treatment with cisplatin and irinotecan whereas paclitaxel and gemcitabine resulted in a considerable reduction of the viability of the cancer cells. Both paclitaxel and gemcitabine treatment resulted in the induction of apoptosis. This sensitivity profile might be due to a particular subset of p53, which reacted with monoclonal antibodies DO-1 and PAb1801 but not with PAb1620 and PAb421. Gemcitabine and paclitaxel are highly efficient in the induction of apoptosis in ovarian cancer cells, which express a particular subset of the growth suppressor protein $\mathrm{p} 53$. Thus, a sensitivity profile for each ovarian carcinoma seems to be highly recommended before starting treatment.
\end{abstract}

\section{Introduction}

Ovarian cancer is one of the leading causes of cancer mortality. It is difficult to detect at an early stage and most of the patients suffer from massive metastatic disease at the time of diagnosis. Despite radical surgery and the application of several potent anti-neoplastic drugs like cisplatin the prognosis still remains poor. The survival rate of patients with advanced ovarian cancer is only $10-20 \%$ (1). Ovarian cancer is nowadays commonly treated with a combination of cisplatin or carboplatin and paclitaxel (2). The cytotoxic effects of cisplatin are primarily mediated by the formation of DNA interstrand and intrastrand cross-links (3). In addition, the cisplatin-induced accumulation

Correspondence to: Professor Mathias Montenarh, Medizinische Biochemie und Molekularbiologie, Universität des Saarlandes, Gebäude 44, D-66421 Homburg, Germany

E-mail: m.montenarh@mx.uni-saarland.de

Key words: apoptosis, gemcitabine, paclitaxel, $\gamma$-irradiation, p53 of p53 following DNA strand breaks also leads to growth arrest or apoptosis (4). Paclitaxel acts by binding to $\gamma$-tubulin, which leads to irreversible microtubule stabilization, thus inhibiting the degradation of the mitotic spindle and subsequently, leads to $\mathrm{G}_{2} / \mathrm{M}$ arrest and apoptosis (5) via p53 dependent and independent pathways (6). Unfortunately, most patients relapse after this first line chemotherapy (7). Some of them can be re-treated effectively with the same agents; but others become platinum-refractory. In such cases a number of other drugs are used such as anthracyclines, topoisomerase inhibitors, nucleoside analogues or vinca alkaloids (8). Irinotecan is one of these drugs that acts as a topoisomerase I inhibitor leading to DNA strand breaks (9). One interesting cytostatic drug, which is gaining attention is gemcitabine, a pyrimidine analogue with considerable success in the treatment of different types of cancer and with modest side effects. Gemcitabine inhibits ribonucleotide metabolism, hinders DNA processing, and increases accumulation of intrastrand adducts and interstrand cross-links, thereby leading to a $G_{1}$ block in the cell cycle. Gemcitabine is generally welltolerated (10).

Despite its long history in the treatment of ovarian carcinoma and its proven curative role in patients with minimal residual disease, the proper role of radiotherapy in the management of this tumor is controversial and not clearly established. Similarly, the potential roles for radiotherapy in the consolidate treatment and as salvage therapy following chemotherapy failure remain controversial (11). There are examples where radiotherapy has proven to be successful (12) and where a combination of radiotherapy and hyperthermia led to the complete remission of an ovarian clear cell adenocarcinoma.

The main aim of all these therapies might be tumor regression through the induction of apoptosis. There are two principal ways of apoptosis, which finally lead to the fragmentation of the DNA and to the decay of the cell into apoptotic bodies, which are finally removed by phagocytes: the receptormediated extrinsic pathway and the mitochondrial intrinsic pathway. One of the late events in the apoptosis pathways is the cleavage of the poly-ADP-ribosyl-polymerase (PARP), a $116-\mathrm{kDa}$ protein into fragments of 89 and $26 \mathrm{kDa}(13)$. A failure in inducing apoptosis might well be due to a nonfunctional cellular regulator such as p53. p53 is activated and accumulates in the cell in response to DNA damage. By inhibiting the activity of the cyclin dependent kinases it forces 
the cell into growth arrest and supports DNA repair activity of the cell. Irreparable damage leads the cell into apoptosis by influencing the balance between pro- and anti-apoptotic proteins (14). In more than $50 \%$ of all tumors p53 is mutated and in many tumors a wild-type p53 is non-functional because of the interaction with an antagonist. As p53 is mainly active at the $\mathrm{G}_{1} / \mathrm{S}$ check-point actual therapeutic strategies try to bypass this check-point, which is mostly defective in cancer cells and hit the $\mathrm{G}_{2} / \mathrm{M}$ check-points of tumor cells by forcing cancer cells into mitotic catastrophe.

To improve the treatment of ovarian cancer it would be beneficial to know the sensitivity profile of cancer cells towards the used chemotherapeutic drugs. We therefore established an in vitro system consisting of two different ovarian carcinoma cell lines: OV-MZ 32 is a serous adenocarcinoma cell line (15), and OvBH-1 cells are derived from an ovarian clear cell carcinoma (16). We treated these cell lines with the drugs, which are usually applied for the treatment of ovarian carcinoma such as cisplatin, paclitaxel, irinotecan and gemcitabine. Since there is also a report on a patient with ovarian cancer in whom complete remission was obtained by a combination of radiotherapy and hyperthermia (12) we moreover irradiated the ovarian carcinoma cell lines. As an important parameter for the success of the treatment we analyzed the induction of apoptosis in the different cell lines. Surprisingly, the conventional treatment with cisplatin and irinotecan and also $\gamma$-irradiation only showed a modest outcome. A very efficient induction of programmed cell death was demonstrated by the application of paclitaxel and especially, of gemcitabine. A combination of both drugs showed no gross synergistic effect. Thus, our results demonstrate the importance of checking each individual ovarian carcinoma for its resistance or sensitivity profile towards chemotherapeutic drugs in order to create an individual therapy. Moreover, we show that gemcitabine or paclitaxel treatment alone is sufficient for an efficient tumor therapy, at least in vitro.

\section{Materials and methods}

Cell lines. OV-MZ-32 is a serous human ovarian adenocarcinoma cell line, which was kindly provided by Dr I. Runnebaum, Freiburg (15). OV-MZ-32 cells carry a 13-bp deletion from codon 314 to codon 318 of the p53 gene. OvBH-1 is a temperature-sensitive ovarian clear cell carcinoma cell line, characterized in detail elsewhere $(16,17)$. Polish Patent Nr. P.327793 protects this cell line. Cells were maintained in DMEM medium with $10 \%$ fetal calf serum in a humidified incubator at $37^{\circ} \mathrm{C}$ with $5 \% \mathrm{CO}_{2}$.

Treatment of the cells with different drugs and $\gamma$-irradiation. Cells were grown to $40 \%$ confluence $24 \mathrm{~h}$ before irradiation. Cells were $\gamma$-irradiated with doses of $0,2,4,6,8$ and $16 \mathrm{~Gy}$. Seventy-two hours after treatment surviving cells were counted in a haemocytometer after dye exclusion.

Gemcitabine hydrochloride (Gemzar ${ }^{\circledR}$, Lilly S.A., France), irinotecan hydrochloride (Campto ${ }^{\circledR}$, Aventis Pharma Ltd., Essex, UK), and cis-platinum (II)-diamine dichloride (Sigma, München, Germany) were dissolved in water in a concentration of $10 \mathrm{mM}$. Paclitaxel (Sigma) was dissolved as $5 \mathrm{mM}$ stock solution in dimethyl sulfoxide (DMSO). Twenty-four hours after seeding the cells drugs were applied in concentrations of $1 \mathrm{nM}, 10 \mathrm{nM}, 100 \mathrm{nM}, 1 \mu \mathrm{M}$ and $10 \mu \mathrm{M}$. Seventy-two hours after treatment the viability of the cells was determined with an MTT assay or the cells were subjected to a Western blot or cytofluorimetric analysis.

MTT assay. Cell proliferation and viability was determined using a colorimetric MTT-based assay (MTT: 3-[4,5-dimethylthiazol-2-yl] 2,5-diphenyl tetrazolium bromide, Sigma-Aldrich, Deisenhofen, Germany). The assay is based on the reduction of the yellow tetrazolium salt MTT to purple formazan crystals by metabolically active cells. $3 \times 10^{3}(\mathrm{OvBH}-1)$ or $5 \times 10^{3}$ (OV-MZ-32) cells/per well were grown in a 96-well plate in a final volume of $100 \mu \mathrm{l}$ culture medium. The MTT labeling reagent $(10 \mu \mathrm{l})(5 \mathrm{mg} / \mathrm{ml} \mathrm{PBS})$ was added to each well. The enzymatic reaction was allowed to take place for at least $4 \mathrm{~h}$ at $37^{\circ} \mathrm{C}$ in a humidified atmosphere. The formation of purple crystals was monitored in a light microscope. The crystals were dissolved by adding $100 \mu \mathrm{l}$ of a solubilization solution [10\% w/v sodium dodecyl sulfate (SDS), $0.01 \mathrm{M} \mathrm{HCl}$ ] overnight at $37^{\circ} \mathrm{C}$. The spectrophotometrical absorbance of the blue dye was determined in a 96-well plate in an ELISA reader at $595 \mathrm{~nm}$.

Cytofluorimetry. For cytofluorimetric analysis cells were washed twice with cold phosphate-buffered saline (PBS) and harvested by trypsinizing. Cells were spun down (400 x g, $4^{\circ} \mathrm{C}, 10 \mathrm{~min}$ ) and resuspended in $200 \mu \mathrm{l} \mathrm{PBS}$. Cells were fixed by adding $2 \mathrm{ml}$ ice-cold $70 \%$ ethanol and left for at least 30 min at $-20^{\circ} \mathrm{C}$. Cells were harvested by centrifugation and resuspended in $800 \mu \mathrm{l}$ PBS. RNase $(100 \mu \mathrm{l})(1 \mathrm{mg} / \mathrm{ml})$ and $100 \mu 1$ propidium iodide $(400 \mu \mathrm{g} / \mathrm{ml})$ were added and cells were incubated for $30 \mathrm{~min}$ at $37^{\circ} \mathrm{C}$ and then sonicated for $30 \mathrm{sec}$ at $4^{\circ} \mathrm{C}$. Cell cycle analysis of the suspension was performed using a Becton-Dickinson FACScan II cytofluorimeter.

Western blot analysis. Proteins were analyzed by SDS polyacrylamide gel electrophoresis according to the procedure of Laemmli (18). For Western blot analysis proteins were transferred to a PVDF membrane by tank blotting with $20 \mathrm{mM}$ Tris/ $\mathrm{HCl}, \mathrm{pH} 8.7,150 \mathrm{mM}$ glycine as transfer buffer. Membranes were blocked in PBS with $0.1 \%$ Tween-20 and 5\% dry milk for $1 \mathrm{~h}$ at room temperature. The membrane was incubated with the primary antibody in PBS Tween-20 with $1 \%$ dry milk for $1 \mathrm{~h}$. The membrane was then washed with PBS Tween-20 three times before incubating with the peroxidase-coupled secondary antibody in a dilution of 1:10000 in PBS Tween20 with $1 \%$ dry milk. Signals were developed and visualized by the Lumilight system of Roche Diagnostics (Mannheim, Germany).

We used monoclonal antibodies DO-1 (Santa Cruz), PAb1801 (Oncogene Science), PAb421 (19) and PAb1620 (20) for the detection of p53. The anti-PARP antibody (Ab-2) (Oncogene Science) was used in a dilution of 1:100 and incubated overnight.

\section{Results}

Viability of different ovarian carcinoma cells after treatment with $\gamma$-irradiation and chemotherapeutic drugs. We used an in vitro system to check the effect of cytostatica and radio- 


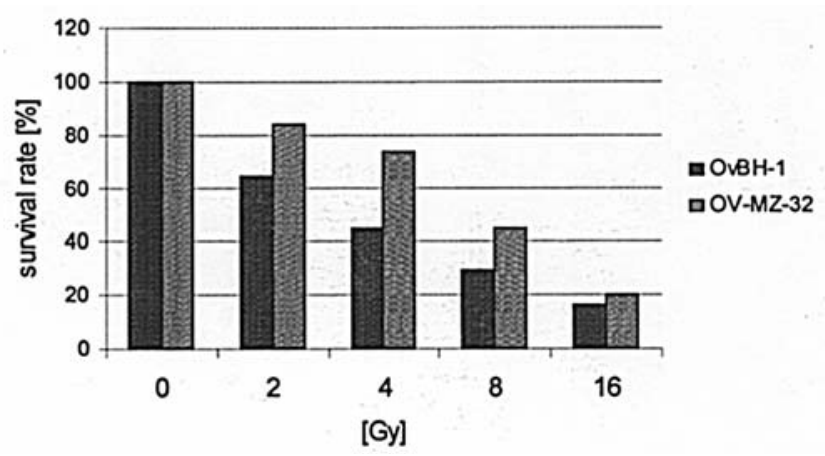

Figure 1. Survival of ovarian cancer cells after $\gamma$-irradiation. Cells were seeded $24 \mathrm{~h}$ before $\gamma$-irradiation. Cells were treated with doses of $0,2,4,8$ or 16 Gy. Seventy-two hours after the treatment living cells were counted in a haemocytometer. The number of non-irradiated cells corresponds to $100 \%$.
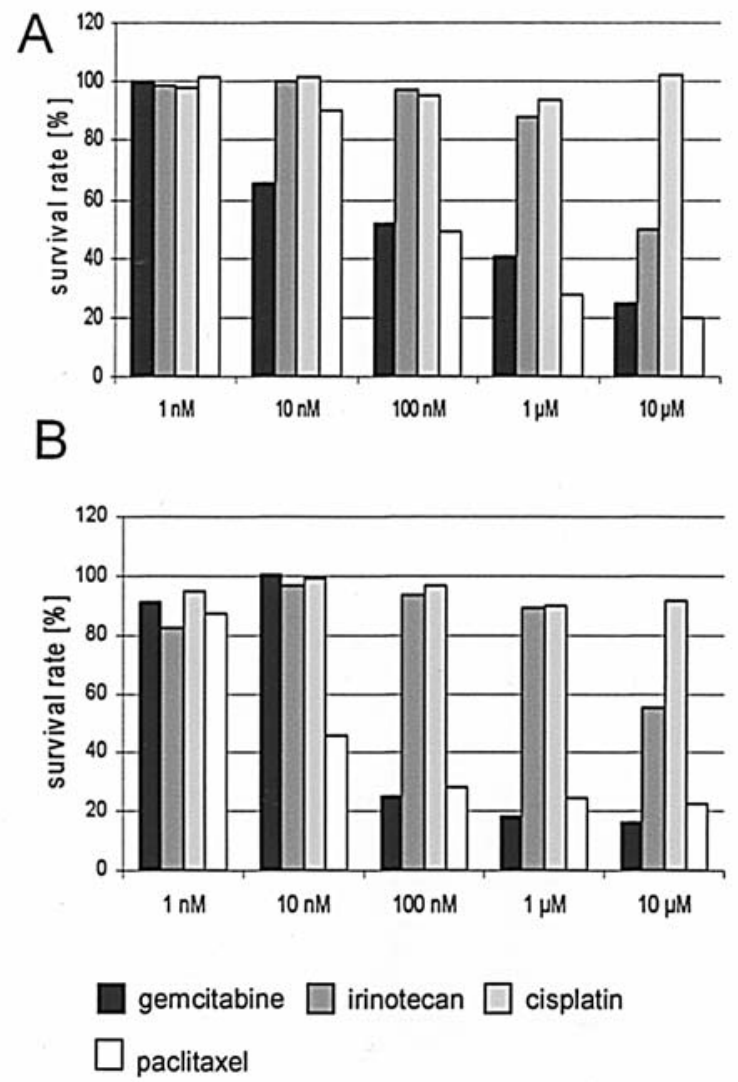

Figure 2. Survival of ovarian carcinoma cells after cytostatica treatment. Twenty-four hours after seeding cells were exposed to the indicated concentrations of cisplatin, irinotecan, paclitaxel or gemcitabine. Seventy-two hours after the treatment the rate of living cells was determined with an MTT assay. An untreated control was set to $100 \%$ (data not shown) to which all other values were referred. (A), OvBH-1; (B), OV-MZ-32.

therapy on ovarian cancer cells. Cells were $\gamma$-irradiated with doses up to $16 \mathrm{~Gy}$ and afterwards, living cells were counted in a haemocytometer. For the comparison of the effect of the radiotherapy the percentage of viable cells was plotted as a function of the radiation dose. The $50 \%$ inhibitory dose $\left(\mathrm{ID}_{50}\right)$ was determined for each cell line based on these curves. As shown in Fig. 1, in general, both cell lines were rather insensitive. However, OV-MZ-32 cells appeared to be more
A

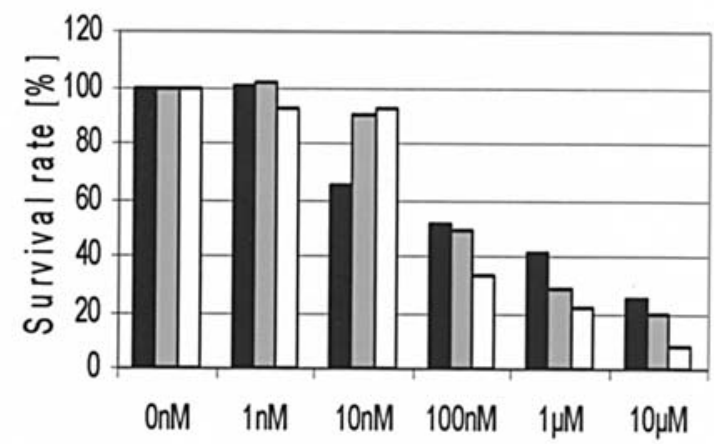

B

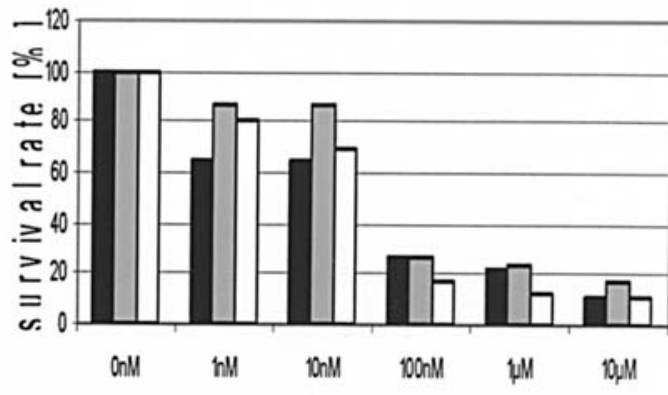

\section{gemcitabine $\square$ paclitaxel}

gemcitabine/paclitaxel

Figure 3. Survival of ovarian carcinoma cells after treatment with gemcitabine and paclitaxel. Twenty-four hours after seeding cells were exposed to the indicated concentrations of gemcitabine, paclitaxel or a combination of both. Seventy-two hours after treatment the rate of living cells was determined with an MTT assay. An untreated control $(0 \mathrm{nM})$ was set to $100 \%$ to which all other values were referred. (A), OvBH-1; (B), OV-MZ-32.

resistant than OvBH-1 cells. Based on the data in Fig. 1 the $\mathrm{ID}_{50}$ doses ranged between around $4 \mathrm{~Gy}$ for OvBH-1 and around 8 Gy for OV-MZ-32 cells indicating that $\gamma$-irradiation is not the first choice for the treatment of ovarian carcinoma.

Next, we analyzed the sensitivity of the ovarian carcinoma cell lines for the treatment with paclitaxel and cisplatin. In addition, we also tested irinotecan and gemcitabine. Cells were treated with concentrations ranging from $1 \mathrm{nM}$ up to $10 \mu \mathrm{M}$ of cisplatin, irinotecan, paclitaxel or gemcitabine. After treatment for $72 \mathrm{~h}$ viability of the cells was controlled with a colorimetric assay. The percentages of the resulting vital cells compared to untreated control cells are presented in Fig. 2. For all cell lines treatment with cisplatin showed no effect on the growth of the cells. We made essentially the same observation when using irinotecan although at the highest concentration $(10 \mu \mathrm{M})$ the viability of the cells was modestly reduced to a growth rate of $50-75 \%$ of the control cells.

A considerable reduction in viability was achieved with gemcitabine and paclitaxel. OV-MZ-32 cells showed a 

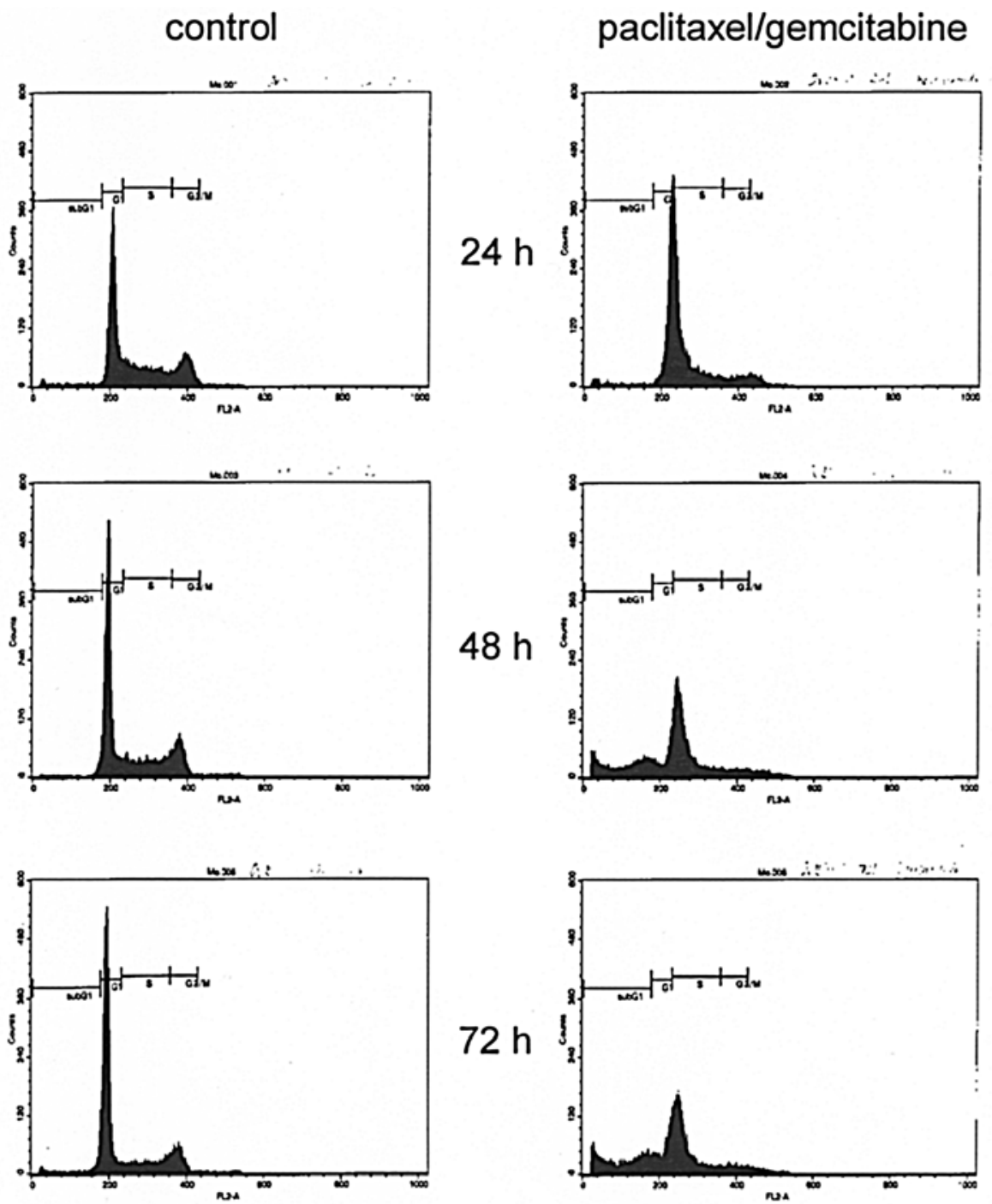

Figure 4. Cytofluorimetry analysis of OvBH-1 cells after treatment with paclitaxel/gemcitabine. OvBH-1 cells were treated with a combination of $100 \mathrm{nM}$ gemcitabine and $100 \mathrm{nM}$ paclitaxel for 24, 48 and $72 \mathrm{~h}$. Cells were fixed with ethanol and stained with propidium iodide. Cell cycle analysis was performed using a FACScan II cytofluorimeter from Becton-Dickinson. Untreated cells served as control.

reduction of $75 \%$ in growth when using $100 \mathrm{nM}$ gemcitabine. Paclitaxel was already effective at a concentration of $10 \mathrm{nM}$ in around half of the cell population. Also, OvBH-1 cells showed a stronger sensitivity towards both drugs with an $\mathrm{ID}_{50}$ of $100 \mathrm{nM}$ for gemcitabine or paclitaxel. In all cases both drugs were more efficient than cisplatin and irinotecan.

In order to analyze whether there is a synergistic effect the viability assays were repeated with a combination of both drugs. The results shown in Fig. 3 demonstrate that the combination of both drugs had some but not a significant effect on the reduction of the growth rate compared to gemcitabine or paclitaxel alone. Thus, we have demonstrated that the ovarian cancer cell lines were rather insensitive towards $\gamma$-irradiation and chemotherapy with cisplatin and irinotecan. However, viability of cells was considerably reduced by the use of paclitaxel and gemcitabine.

Apoptosis induction in ovarian cancer cells after treatment with gemcitabine and paclitaxel. Since we observed a considerable reduction in metabolically active cells after treatment with gemcitabine or paclitaxel we now asked whether treatment with these drugs provokes the induction of apoptosis. We performed two different assays for the detection of programmed cell death in treated cells: a cytofluorimetric analysis and a Western blot analysis to show the cleavage of poly-ADPribosyl-polymerase (PARP). For the cytofluorimetric analysis we treated cells for $72 \mathrm{~h}$ with $100 \mathrm{nM}$ gemcitabine or $100 \mathrm{nM}$ paclitaxel or a combination of $100 \mathrm{nM}$ gemcitabine/100 nM paclitaxel. Cells were harvested and the DNA stained with propidium iodide. An example of a cell cycle profile is shown in Fig. 4 for OvBH-1, which had been treated with the combination of both drugs. In comparison to the control cells the sub- $\mathrm{G}_{1}$-population significantly increased from about 4 to $26 \%$ after $48 \mathrm{~h}$ and $28 \%$ after $72 \mathrm{~h}$. The sub- $\mathrm{G}_{1}$-population represents cells with fragmented DNA. Thus, nearly one third of the cell population is committed to apoptosis. Moreover, we observed an increase in the S-phase cells from about $25-30 \%$ to $45-50 \%$. Concomitantly, the amount of $\mathrm{G}_{2^{-}}$and especially $\mathrm{G}_{1}$-cells decreased drastically. The data for the cell lines treated with both drugs separately or in combination are 
Table I. Percentage values of treated and untreated cells in the different cell cycle phases.

\begin{tabular}{lcccr}
\hline & Sub-G & $\mathrm{G}_{1}$ & $\mathrm{~S}$ & $\mathrm{G}_{2} / \mathrm{M}$ \\
\hline $\begin{array}{l}\text { Ov-MZ-32, } \\
\text { Pac 72 h }\end{array}$ & 56.29 & 23.27 & 11.44 & 8.77 \\
$\begin{array}{l}\text { Ov-MZ-32, } \\
\text { Gem 72 h }\end{array}$ & 59.83 & 23.17 & 11.72 & 5.47 \\
$\begin{array}{l}\text { Ov-MZ-32, } \\
\text { Pac/Gem 72 h }\end{array}$ & 31.9 & 15.95 & 25.09 & 15.98 \\
$\begin{array}{l}\text { Ov-MZ-32, } \\
\text { control }\end{array}$ & 5.96 & 36.5 & 10.9 & 36.3 \\
$\begin{array}{l}\text { Ov-BH1, } \\
\text { Pac 72 h }\end{array}$ & 10.27 & 6.19 & 53.12 & 16.19 \\
$\begin{array}{l}\text { Ov-BH1, } \\
\text { Gem 72 h }\end{array}$ & 23.6 & 6.31 & 42.13 & 13.57 \\
$\begin{array}{l}\text { Ov-BH1, } \\
\text { Pac/Gem 72 h }\end{array}$ & 27.95 & 18.43 & 44.18 & 6.51 \\
$\begin{array}{l}\text { Ov-BH1, } \\
\text { control }\end{array}$ & 6.78 & 57.15 & 20.57 & 14.1 \\
\hline
\end{tabular}

Pac, paclitaxel 100 nM; Gem, gemcitabine $100 \mathrm{nM}$.

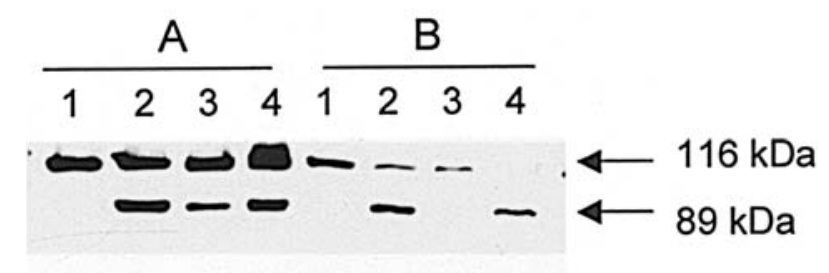

Figure 5. PARP cleavage after treatment of ovarian cancer cells with gemcitabine and paclitaxel. Cells were treated with $100 \mathrm{nM}$ gemcitabine (lane 2), $100 \mathrm{nM}$ paclitaxel (lane 3) or a combination of both (lane 4) for $72 \mathrm{~h}$. Untreated cells (lane 1) served as control. Cell extract $(150 \mu \mathrm{g})$ was loaded on a $10 \%$ SDS polyacrylamide gel and analyzed by Western blot with the PARP-specific antibody Ab-2. Signals were visualized with a PODconjugated secondary anti-mouse antibody and the Lumilight system. (A), OV-MZ-32; (B), OvBH-1.

summarized in Table I. Although there are some variations in the efficiency for both drugs for the studied cell lines the combination of paclitaxel and gemcitabine showed no clearly visible synergistic effect. So far our data provided strong evidence that the chemotherapy of ovarian cancer with paclitaxel and gemcitabine applied separately and in combination induced apoptosis.

To verify the data concerning the induction of apoptosis we performed a Western blot analysis in which we checked the cleavage of PARP. PARP is a $116-\mathrm{kDa}$ protein, which is processed by caspase 3 into fragments of about 89 and $26 \mathrm{kDa}$. In the Western blot analysis we used an antibody, which recognizes the full-length protein and the $89-\mathrm{kDa}$ fragment and thus allows a follow-up of the apoptosis induction in response to the treatment. The results are shown in Fig. 5. In every

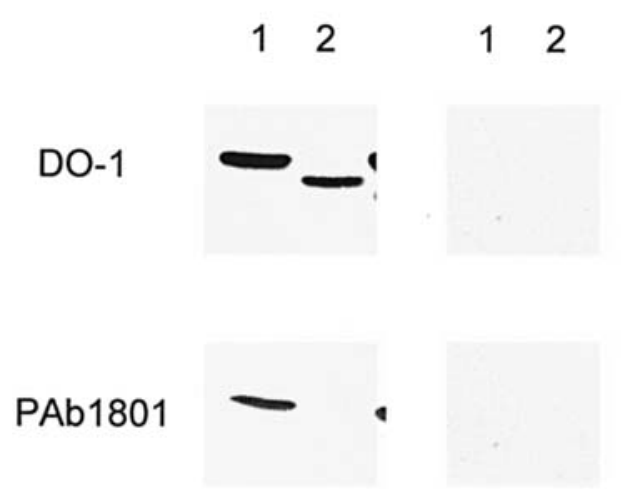

PAb421

Figure 6. Identification of p53 in ovarian cancer cells with different p53 antibodies. Protein $(50 \mu \mathrm{g})$ from a cell extract from OvBH-1 and OV-MZ-32 cells were loaded on a $10 \%$ SDS polyacrylamide gel and analyzed by Western blot with the p53 specific monoclonal antibodies DO-1, PAb421, PAb1620 and PAb1801. Protein bands were visualized with a POD-conjugated secondary anti-mouse antibody and the Lumilight system. (Lane 1), OvBH-1; (lane 2), OV-MZ-32.

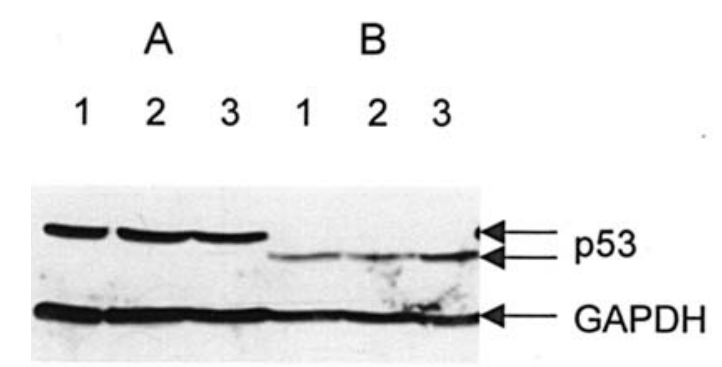

Figure 7. Expression of p53 in ovarian carcinoma cells after $\gamma$-irradiation. Cells were $\gamma$-irradiated with 4 Gy and harvested after $1 \mathrm{~h}$ (lane 2 ) or after $3 \mathrm{~h}$ (lane 3), respectively. Non-irradiated cells served as control (lane 1). Cell extract $(30 \mu \mathrm{g})$ was loaded on a $10 \%$ SDS polyacrylamide gel and analyzed by Western blot with the p53-specific antibody DO-1. Signals were visualized with a POD-conjugated secondary anti-mouse antibody and the Lumilight system. A GAPDH-specific antibody was used as loading control. (A), OvBH-1; (B), OV-MZ-32.

case we detected the full-length protein. Upon treatment with $100 \mathrm{nM}$ gemcitabine we constantly observed the processing of the full-length protein to the $89-\mathrm{kDa}$ fragment. We also reproducibly detected the cleavage of PARP in response to the treatment with paclitaxel, but in contrast to the treatment with gemcitabine it turned out to be much weaker. The combination of both drugs also led to the cleavage of PARP, but the effect was obviously not stronger than with gemcitabine alone. Thus, these data support the observation that by the treatment with cytostatic drugs cells are committed to apoptosis; for the induction of apoptosis in the studied cell lines treatment with paclitaxel or with gemcitabine alone seems to be sufficient and efficient.

The role of p53 in the apoptosis induction in ovarian cancer cells. Trying to analyze the p53 protein in both cell lines we found that $\mathrm{p} 53$ could only be detected with the monoclonal antibodies DO-1 and PAb1801 but not with PAb421 and PAb1620 (Fig. 6). Next, we analyzed the response of the p53 protein upon $\gamma$-irradiation. Cells were $\gamma$-irradiated with 4 Gy and extracted either after $1 \mathrm{~h}$ or after $3 \mathrm{~h}$. The cell extracts were analyzed on an SDS polyacrylamide gel followed by a Western blot. 
A

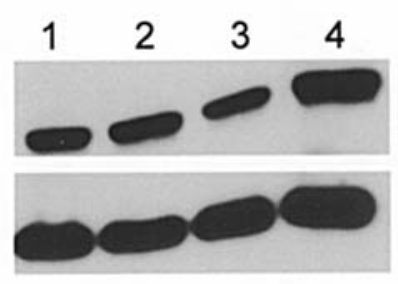

p53

GAPDH

\section{B}

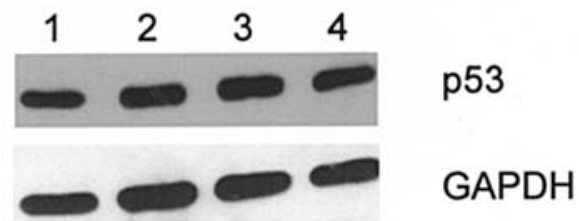

Figure 8. Expression of p53 in ovarian carcinoma cells after treatment with gemcitabine and paclitaxel. Cells were treated with $100 \mathrm{nM}$ gemcitabine (lane 2), $100 \mathrm{nM}$ paclitaxel (lane 3) or a combination of both (lane 4) for $72 \mathrm{~h}$. Untreated cells (lane 1) served as control. Cell extract $(50 \mu \mathrm{g})$ was loaded on a $10 \%$ SDS polyacrylamide gel and analyzed by Western blot with the p53-specific antibody DO-1. Signals were visualized with a PODconjugated secondary anti-mouse antibody and the Lumilight system. A GAPDH-specific antibody was used as loading control. (A), OV-MZ-32; (B), OvBH-1.

p53 was detected with monoclonal antibody DO-1. As shown in Fig. 7, p53 was expressed in comparable amounts in both cell lines and independently of the time-points after radiation. Thus, these data indicated that there is no stabilization of p53. Moreover, there was no induction of $\mathrm{p} 21^{\mathrm{WAF} 1}$, one of the downstream targets of p53 (data not shown).

Subsequently, we analyzed the reaction of p53 after treatment with gemcitabine and paclitaxel. Seventy-two hours after drug application cells were harvested and protein extracts were subjected to a Western blot analysis with the p53 specific monoclonal antibody DO-1. As shown in Fig. 8, p53 could be detected in both cell lines, either treated or untreated. Upon treatment with the different drugs we did not observe accumulation of the p53 protein. Moreover, also in this case the p53 protein does not seem to be active as transcription factor since at least one of the major transactivated targets $\mathrm{p} 21^{\mathrm{WAF} 1}$ could not be identified. Thus, the apoptosis induction by paclitaxel or gemcitabine does not rely on the presence of a functionally active p53. Thus, we conclude that the chemotherapy of the ovarian cancer cells leads to apoptosis without the induction of $\mathrm{p} 53$.

\section{Discussion}

Clear cell ovarian carcinoma has a poor prognosis mainly because its resistance to cytostatica and in particular against platinum compounds. Recently, a patient was reported with clear cell carcinoma of the ovary in whom complete remission was obtained by a combination of radiotherapy and hyperthermia (12). Moreover, also an established clear cell adenocarcinoma cell line turned out to be rather resistant to chemotherapy with cisplatin, irinotecan, paclitaxel and gemcitabine whereas it was very sensitive to $\gamma$-irradiation. A $50 \%$ growth inhibition was achieved with a dose of $1.8 \mathrm{~Gy}$ (21) indicating a high radiation sensitivity of this type of ovarian cancer. In contrast our ovarian clear cell carcinoma cell line was rather resistant to $\gamma$-irradiation with an $\mathrm{ID}_{50}$ between 4 and 8 Gy. Thus, it seems to us that a general statement about a radiation therapy is impossible and each patient with ovarian clear cell carcinoma possesses an individual sensitivity.

It is known that cisplatin induced apoptosis in human ovarian cancer cells (22). However, many other tumors are intrinsically resistant against cisplatin. Some tumors, which were initially sensitive to cisplatin, develop resistance during treatment. It was the most surprising result of our study that the ovarian carcinoma cell lines analyzed appeared to be insensitive for cisplatin treatment. This might be explained by the observation that cisplatin resistant tumor cells show an elevated level of the p53 protein. Sequence analysis revealed that this p53 could either be mutant or wild-type $(22,23)$. Moreover, these tumor cells also exhibited a less reduced inhibition of DNA synthesis after $\gamma$-irradiation.

Irinotecan is a cornerstone drug in the management of metastatic colorectal cancer (24). It is a camptothecin derivative that inhibits topoisomerase I. It is believed that such an inhibitor stabilizes a DNA/topoisomerase I complex and interacts with the replication machinery to cause cell death. In the present study irinotecan inhibited cell growth of ovarian cancer cells only at high concentrations. However, there was no indication for cell death.

Paclitaxel is an antimicrotubule agent blocking cell division by interfering with the function of the mitotic spindle (25). Ovarian carcinomas with mutant p53 were described to be more responsive to a paclitaxel-based chemotherapy than p53 wildtype expressing tumors (26). In contrast, Debernardis et al could not find a correlation between the sensitivity of human ovarian cancer cells to paclitaxel and the p53 status and therefore suggested that paclitaxel may have the ability to activate apoptosis in the absence of a functional wild-type p53 (27). This later finding is in accordance with other observations in glioma cells and in renal cell carcinoma $(28,29)$. Our results indicate that paclitaxel is very efficient in the treatment of ovarian carcinoma cells inducing apoptosis. Paclitaxel is also a highly effective chemotherapeutic agent against adenocarcinomas and squamous cell carcinomas of the esophagus where it was also shown to induce apoptosis (30).

Cytotoxicity of gemcitabine is related to the cellular accumulation of gemcitabine triphosphate inducing a $\mathrm{G}_{0} / \mathrm{G}_{1^{-}}$ and S-phase arrest in tumor cells (31). Gemcitabine $\left(2^{\prime}, 2^{\prime}-\right.$ difluorodeoxycytidine) has improved the survival of patients with many different tumors (32). Mechanistic studies have demonstrated that there are at least two major pathways through which gemcitabine acts: i) direct inhibition of DNA synthesis by formation of the triphosphate form, and ii) inhibition of ribonucleotide reductase, which results in the depletion of deoxynucleoside triphosphates necessary for DNA synthesis (33). In the case of pancreatic cancer gemcitabinebased combination chemotherapy has been shown to give better results than gemcitabine alone (34). In the case of breast and non-small cell lung cancers it was shown that paclitaxel increased the accumulation of $\mathrm{dFdCTP}$, incorporation of gemcitabine into RNA and apoptosis $(35,36)$. In the case of ovarian cancer cells we did not observe a significant increase in the response using a combination of both drugs. As shown herein, both paclitaxel and gemcitabine applied separately 
are very efficient in its activity in inducing growth arrest and apoptosis. A combination of paclitaxel and gemcitabine failed to show any clearly visible synergistic effect.

The molecular pathway by which gemcitabine caused apoptosis has not been fully defined. In the case of non-small lung cancer (NSCLC) it was found that gemcitabine induced apoptotic cell death via the Bcl-2 dependent caspase-9 activation pathway. Moreover, upon gemcitabine treatment the extracellular signal-regulated kinase (ERK) pathway was induced. Since these studies were performed in $\mathrm{p} 53^{-/-}$cells it was clear that the induction of these pathways is p53 independent (37).

Alterations in the p53 gene in ovarian carcinoma cell lines are rarely described $(22,23,38)$. We found that both cell lines expressed high levels of p53 indicating a stabilization and inactivation of the protein. In the case of OvBH-1 cells this stabilization is not due to a mutation in the p53 gene because sequence analysis revealed only a neutral genetic polymorphism $(17,39)$. OV-MZ-32 cells express a p53 mutant with a deletion between amino acids 314 and 318 (15). This deletion affects the cdc2 phosphorylation site at position 315 , which is known to regulate the sequence specific DNA binding of p53 and conformational changes in the p53 protein (40). It was a very interesting observation that $\mathrm{p} 53$ from both cell lines reacted only with the p53 specific monoclonal antibodies DO-1 and PAb1801, but not with PAb421 and PAb1620. Antibody DO-1 reacts with the epitope ${ }^{20}$ SDLWKL $^{25}$ in the N-terminus of $\mathrm{p} 53$ in an unphosphorylated form $(41,42)$. A failure to interact with monoclonal antibody PAb421 indicates that p53 is phosphorylated at Ser 378 or acetylated at Ser $373(43,44)$. Monoclonal antibody PAb1620 recognizes p53 in the wildtype conformation $(45,46)$. PAb1801 reacts with the sequence between amino acids 46 and 55 (47) which seems not to be affected by specific modifications or functions of $\mathrm{p} 53$. Thus, our data indicate the presence of a particular subset of p53 in these ovarian carcinoma cells. This is further supported by the observation that neither $\mathrm{p} 21^{\mathrm{WAF} 1}$ nor mdm-2 is transactivated upon treatment with the different drugs indicating the presence of an at least partially inactive p53. Furthermore, these data demonstrate that gemcitabine and paclitaxel induce a p53 independent pathway of apoptosis in the ovarian cancer cells.

In conclusion, our data favor the view that a general therapy strategy for ovarian cancer seems to be inadequate. Information on the p53 status seems to be important before starting therapy. As shown here a sensitivity profile for $\gamma$ irradiation or for different drugs seems to be individually differentiated.

\section{Acknowledgements}

We thank Dr. Andrea Krempler for the expert help with the cytofluorimetric analysis. We greatly appreciate the gift of OV-MZ-32 cells from Dr. I. Runnebaum, Freiburg, Germany and for OvBH-1 by Dr. Julia Bar from Medical University, Wroclaw, Poland. This work was supported by HOMFOR 2004/28Mo and by the German/Polish Scientific Technology Cooperation Joint project $\mathrm{Nr} \mathrm{C} / 13161$.

\section{References}

1. Boente MP, Hurteau J, Rodriguez GC, Bast RC Jr and Berchuck A: The biology of ovarian cancer. Curr Opin Oncol 5: 900-907, 1993.

2. Du Bois A and Pfisterer J: Future options for first-line therapy of advanced ovarian cancer. Int J Gynecol Cancer 15 (Suppl. 1): S42-S50, 2005.

3. Perez RP: Cellular and molecular determinants of cisplatin resistance. Eur J Cancer 34: 1535-1542, 1998.

4. Niedner H, Christen R, Lin X, Kondo A and Howell SB: Identification of genes that mediate sensitivity to cisplatin. Mol Pharmacol 60: 1153-1160, 2001.

5. Dumontet C and Sikic BI: Mechanisms of action of and resistance to antitubulin agents: microtubule dynamics, drug transport and cell death. J Clin Oncol 17: 1061-1070, 1999.

6. Wang LG, Liu XM, Kreis W and Budman DR: The effect of antimicrotubule agents on signal transduction pathways of apoptosis: a review. Cancer Chemother Pharmacol 44: 355-361, 1999.

7. Greenlee RT, Hill-Harmon MB, Murray T and Thun M: Cancer statistics, 2001. CA Cancer J Clin 51: 15-36, 2001.

8. Harries M and Kaye SB: Recent advances in the treatment of epithelial ovarian cancer. Expert Opin Investig Drugs 10: 1715-1724, 2001.

9. Gershenson DM: Irinotecan in epithelial ovarian cancer. Oncology 16: 29-31, 2002

10. Bookman MA: Gemcitabine monotherapy in recurrent ovarian cancer: from the bench to the clinic. Int J Gynecol Cancer 15 (Suppl. 1): S12-S17, 2005

11. Cardenes H and Randall ME: Radiotherapy in epithelial ovarian cancer: state of the art. World Health Forum 10: 335-352, 2000.

12. Suzuki M, Saga Y, Tsukagoshi S, Tamura N and Sato I: Recurrent ovarian clear cell carcinoma: complete remission after radiation in combination with hyperthermia; a case study and in vitro study. Cancer Biother Radiopharm 15: 625-628, 2000 .

13. Kaufmann SH, Desnoyers S, Ottaviano Y, Davidson NE and Poirier GG: Specific proteolytic cleavage of poly(ADP-ribose) polymerase: an early marker of chemotherapy-induced apoptosis. Cancer Res 53: 3976-3985, 1993.

14. Haupt S, Berger M, Goldberg Z and Haupt Y: Apoptosis - the p53 network. J Cell Sci 116: 4077-4085, 2003.

15. Wu Q, Kreienberg R and Runnebaum IB: Growth suppression of human ovarian carcinoma OV-MZ-2a and OV-MZ-32 cells mediated by gene transfer of wild-type p53 enhanced by chemotherapy in vitro. J Cancer Res Clin Oncol 126: 139-144, 2000.

16. Bar JK and Harlozinska A: Morphological and phenotypic characterization of a new established ovarian carcinoma cell line (OvBH1). Anticancer Res 20: 2975-2980, 2000.

17. Bar JK, Harlozinska A, Kartarius S, Montenarh M, Wyrodek E, Parkitna JMR, Kochman M and Ozyhar A: Temperaturesensitive ovarian carcinoma cell line (OvBH-1). Jpn J Cancer Res 93: 976-985, 2002.

18. Laemmli UK: Cleavage of structural proteins during the assembly of the head of bacteriophage T4. Nature 227: 680-682, 1970.

19. Harlow E, Crawford LV, Pim DC and Williamson NM: Monoclonal antibodies specific for the SV40 tumor antigens. J Virol 39: 861-869, 1981.

20. Ball RK, Siegl B, Quellhorst S, Brandner G and Braun DG: Monoclonal antibodies against simian virus 40 nuclear large tumour antigen: epitope mapping, papova virus cross-reaction and cell surface staining. EMBO J 3: 1485-1491, 1984.

21. Saga Y, Suzuki M, Machida S, Ohwada M and Sato I: Establishment of a new cell line (TAYA) of clear cell adenocarcinoma of the ovary and its radiosensitivity. Oncology 62: 180-184, 2002.

22. Fajac A, Da Silva J, Ahomadegbe JC, Rateau JG, Bernaudin JF, Riou G and Bénard J: Cisplatin-induced apoptosis and $p 53$ gene status in a cisplatin-resistant human ovarian carcinoma cell line. Int J Cancer 68: 67-74, 1996.

23. Brown R, Clugston C, Burns P, Edlin A, Vasey P, Vojtesek B and Kaye SB: Increased accumulation of p53 protein in cisplatinresistant ovarian cell lines. Int J Cancer 55: 678-684, 1993.

24. Douillard JY: Irinotecan-based regimens in the adjuvant therapy of colorectal cancer. Clin Colorectal Cancer 5 (Suppl. 1): S34-S37, 2005. 
25. Jordan MA, Toso RJ, Thrower D and Wilson L: Mechanism of mitotic block and inhibition of cell proliferation by taxol at low concentrations. Proc Natl Acad Sci USA 90: 9552-9556, 1993.

26. Lavarino C, Delia D, Di Palma S, Zunino F and Pilotti S: p53 in drug resistance in ovarian cancer. Lancet 349: 1556-1556, 1997.

27. Debernardis D, Siré EG, De Feudis P, Vikhanskaya F, Valenti M, Russo P, Parodi S, D'Incalci M and Broggini M: p53 status does not affect sensitivity of human ovarian cancer cell lines to paclitaxel. Cancer Res 57: 870-874, 1997.

28. Reinecke P, Kalinski T, Mahotka C, Schmitz M, Dejosez M, Gabbert HE and Gerharz CD: Paclitaxel/Taxol sensitivity in human renal cell carcinoma is not determined by the p53 status. Cancer Lett 222: 165-171, 2005.

29. Borbé R, Rieger J and Weller M: Failure of taxol-based combination chemotherapy for malignant glioma cannot be overcome by $\mathrm{G}_{2} / \mathrm{M}$ check-point abrogators or altering the $\mathrm{p} 53$ status. Cancer Chemother Pharmacol 44: 217-227, 1999.

30. Faried A, Faried LS, Kimura H, Sohda M, Nakajima M, Miyazaki T, Kato H, Kanuma T and Kuwano H: Differential sensitivity of paclitaxel-induced apoptosis in human esophageal squamous cell carcinoma cell lines. Cancer Chemother Pharmacol 57: 301-308, 2006 .

31. Kaye SB: New antimetabolites in cancer chemotherapy and their clinical impact. Br J Cancer 78 (Suppl. 3): S1-S7, 1998.

32. Burris HA III, Moore MJ, Andersen J, Green MR, Rothenberg ML, Modiano MR, Cripps MC, Portenoy RK, Storniolo AM, Tarassoff P, Nelson R, Dorr FA, Stephens CD and von Hoff DD: Improvements in survival and clinical benefit with gemcitabine as first-line therapy for patients with advanced pancreas cancer: a randomized trial. J Clin Oncol 15: 2403-2413, 1997.

33. Huang P, Chubb S, Hertel LW, Grindey GB and Plunkett W: Action of 2',2'-difluorodeoxycytidine on DNA synthesis. Cancer Res 51: 6110-6117, 1991.

34. Tsai JY, Iannitti DA and Safran H: Combined modality therapy for pancreatic cancer. Semin Oncol 30: 71-79, 2003.

35. Kroep JR, Giaccone G, Tolis C, Voorn DA, Loves WJ, Groeningen CJ, Pinedo HM and Peters GJ: Sequence dependent effect of paclitaxel on gemcitabine metabolism in relation to cell cycle and cytotoxicity in non-small-cell lung cancer cell lines. Br J Cancer 83: 1069-1076, 2000.

36. Kroep JR, Giaccone G, Voorn DA, Smit EF, Beijnen JH, Rosing H, van Moorsel CJ, van Groeningen CJ, Postmus PE, Pinedo HM and Peters GJ: Gemcitabine and paclitaxel: pharmacokinetic and pharmacodynamic interactions in patients with nonsmall-cell lung cancer. J Clin Oncol 17: 2190-2197, 1999.
37. Chang GC, Hsu SL, Tsai JR, Wu WJ, Chen CY and Sheu GT: Extracellular signal-regulated kinase activation and $\mathrm{Bcl}-2$ downregulation mediate apoptosis after gemcitabine treatment partly via a p53-independent pathway. Eur J Pharmacol 502: 169-183, 2004.

38. Yaginuma $\mathrm{Y}$ and Westphal $\mathrm{H}$ : Abnormal structure and expression of the p53 gene in human ovarian carcinoma cell lines. Cancer Res 52: 4196-4199, 1992

39. Schlade-Bartusiak K, Sasiadek MM, Bar J, Urbschat S, Blin N, Montenarh $\mathrm{M}$ and Harlozinska A: Cytogenetic and molecular cytogenetic characterisation of the stable ovarian carcinoma cell line (OvBH-1). Cancer Genet Cytogenet 164: 10-15, 2006.

40. Wang Y and Prives C: Increased and altered DNA binding of human $\mathrm{p} 53$ by $\mathrm{S}$ and $\mathrm{G} 2 / \mathrm{M}$ but not $\mathrm{G} 1$ cyclin-dependent kinases. Nature 376: 88-91, 1995.

41. Stephen CW, Helminen P and Lane DP: Characterisation of epitopes on human p53 using phage-displayed peptide libraries: Insights into antibody-peptide interactions. J Mol Biol 248: 58-78, 1995.

42. Vojtesek B, Bártek J, Midgley CA and Lane DP: An immunochemical analysis of the human nuclear phosphoprotein $\mathrm{p} 53$. New monoclonal antibodies and epitope mapping using recombinant p53. J Immunol Methods 151: 237-244, 1992.

43. Shaw P, Freeman J, Bovey R and Iggo R: Regulation of specific DNA binding by p53: evidence for a role for O-glycosylation and charged residues at the carboxy-terminus. Oncogene 12: 921-930, 1996.

44. Otvos L Jr, Hoffmann R, Xiang ZQ, O I, Deng HY, Wysocka M, Pease AM, Rogers ME, Blaszczyk-Thurin M and Ertl HCJ: A monoclonal antibody to a multiphosphorylated, conformational epitope at the carboxy-terminus of p53. Biochim Biophys Acta Mol Cell Res 1404: 457-474, 1998.

45. Milner JA, Cook A and Sheldon M: A new anti-p53 monoclonal antibody, previously reported to be directed against the large $\mathrm{T}$ antigen of simian virus 40. Oncogene 1: 453-455, 1987.

46. Gannon JV, Greaves R, Iggo R and Lane DP: Activating mutations in $\mathrm{p} 53$ produce a common conformational effect. A monoclonal antibody specific for the mutant form. EMBO J 9: 1595-1602, 1990.

47. Banks L, Matlashewski G and Crawford LV: Isolation of human p53 specific monoclonal antibodies and their use in the studies of human p53 expression. Eur J Biochem 159: 529-534, 1986. 